\title{
OPEN
}

\section{0 \\ Healthy Industries and Unhealthy Populations: Lessons from Indian Problem-Solving}

Smita Srinivas

\section{Introduction}

The Indian health industry, with substantial pharmaceuticals and biopharmaceuticals capability, has been called 'Supplier to the World'. This industry has had three defining policy environments running from 1950 to 2000 , the last of which is arguably still ongoing. These three environments are distinct market environments, in which the range of market instruments used has been notable and the public gains to which they have been put have been noteworthy (Srinivas, 2004; 2012).

In earlier work (Srinivas, 2012) I have provided an explanatory framework for addressing the long timeline this history represents in the political economy of health plans in a late industrial push. In the process of analyzing 50 years of capability building, that study demonstrated that India had accomplished a great deal on the supply of medicines, especially generics, vaccines, and diagnostic kits, but was far less impressive in its health outcomes. This chapter builds further on the analysis in that work, but specifically turns its attention to problem-solving: the type of state capacity required to reconcile industrial and health goals as an essential part of development plans (Srinivas, 2014a). In examining the experience of the First Market Environment, this chapter argues that no explanation of its history is complete, indeed at all relevant, unless we attend to why a state so capable along one dimension can be so wanting in another (Srinivas, 2004; 2012). ${ }^{1}$

\section{The importance of India's 'First Market Environment'}

The First Market Environment (FME) had two distinct market phases: Phase I, from 1950 through the 1960s, and then Phase II running still 
powerfully until the late 1970 s. Phase I was the public sector production effort under immense state regulation. This period included the Industries Development and Regulation Act (IDRA) of the 1950s that had been designed to boost indigenous production, diversification and investment, followed by the Industrial Policy Resolution of 1956, the Monopoly and Restrictive Trade Practices Act of 1969 and the Drugs (Display of Prices) Order promulgated in 1962 which was then adapted many times over in both the First and Second Market Environments.

In contrast to Phase I of the FME during which the public sector led in most respects, Phase II of the FME was marked by a focus on Indian private firms. Again, the state was busy. Its actions included the withdrawal of permissions for industrial diversification to foreign-owned firms in 1970, the Drug Price Control Order (DPCO) in 1970 and two changes to the Indian Patent Act in 1970 and 1972. Then, in 1978, the New Drug Policy (NDP) of the Government of India followed. The NDP provided explicit goals (although some in conflict) and three powerful categories of its own for drugs and their production licenses: 17 essential drugs preferentially and solely allocated to the public sector, 27 drugs for production only by Indian firms and 64 drugs open to production by anyone (for details, see Srinivas, 2012: chapter 3).

The Second Market Environment (SME) overlaps slightly with Phase II of the FME in the continuing focus on essential medicines. It runs from the 1980s and into the 1990s. However, the SME is distinct in the receding power of the state and the visibility instead of three powerful international effects on Indian firms especially in the 1980s. These included the three 'Ws': the Waxman-Hatch Act of the US (1984), which provided strong incentives for foreign companies that manufactured generics; the WTO's new pressures (1985) on the Trade in Intellectual Property Rights (TRIPs) harmonization and patent reforms; and the WHO and other multilateral agencies' procurement efforts for vaccines and other drugs which disproportionately influenced the technical standards of production (Srinivas, 2004; 2012).

In summary, Phase I of the FME built a political rhetoric of universal access while using strong state controls of the market and privileges of the public sector; Phase II of the FME showed a strong push to domestic, private sector capabilities while using public health drugs such as antibiotics to channel both policy design and private sector behaviour. Indigenous supply capabilities were therefore built over the two Phases, first in the public, then in the private sector, of deep investments, slow technological learning and directed technology transfer. By the end 
of the FME in the early 1980s, India had emerged as a redoubtable contender amongst developing nations with pharmaceutical capability, and was challenging even some industrialized economies.

The industrial capabilities of the FME were built with clearer plans for public health - such as the supply of essential medicines - than in any subsequent period (Srinivas, 2004; 2012). Unlike the FME, which was inward-looking in order to build indigenous capabilities, the state in the SME especially from the early 1980s used a variety of market and nonmarket instruments to induce firms to export. Because of the considerable capabilities built in the FME, private indigenous firms stood to make lucrative gains from export markets. Unlike the FME, the SME through the overseas buying instruments of the 1980s was determinedly focussed on upgrading for export markets and on what I have argued elsewhere is the welfare-state priorities of other nations, not necessarily those of India (Srinivas, 2011; 2012).

The SME acted as an important culling zone for firms that were internationally uncompetitive. It also heralded international influences on Indian firms that could not be carefully scripted and regulated by the state. With growing vaccine capability alongside generics, the SME also signalled the growing attraction of large-scale procurement from multilateral agency buyers such as UNICEF and the WHO. The state was undoubtedly less able to control export markets.

Finally, what followed and arguably still exists is a less distinct Third Market Environment (TME) associated with technological shifts in biopharmaceuticals begun in the 1980s and into the 2000s. In important respects these capabilities grew alongside and converged with vaccines in the SME, and with a range of other products and processes in the TME. The state in the TME was far less visible relative to the FME, but more decisive than in the SME. Yet, because of shifting technological considerations, the state's control of domestically owned indigenous private firms far was less than in even the SME.

This Third Market Environment provides an uncertain regulatory environment for new technological frontiers, where the national ownership and national priorities are more ambiguous. Substantial mergers and acquisitions have occurred, new technology capabilities are emerging and new regulatory zones in science and engineering are being explored. Furthermore, manufacturing capabilities have taken something of a backseat to the build-out of private sector opportunities in insurance, logistics, clinics, hospitals and so forth. Technological advances have created the need for a fundamental new balancing between production capabilities and the certainty of access to medicines. 


\section{Problem-solving versus state capacity}

The three market environments exemplify different tensions arising from growing supply capabilities. How then can industrial and health goals be reconciled as an essential element of development planning? The argument here is that to address this question it is insufficient to focus on the diffuse notion of state capacity. Rather, much more can be induced from a focus on problem-solving, to see how industrial capabilities can inch closer to health outcomes. Should the health industry be an economic engine or a means to healthier populations? If it is a means, then the outcomes should be measured in terms of healthier populations. If it is an end, then some troubling developmental tensions remain.

What, then, is missing in the explanations to date? The two-decade period of the FME requires dissection because it is tempting to see the technological supply-side gains from start to finish in the relatively straightforward terms of a move from less to more capable state and firms. Without the detailed analysis of subsequent environments and of the state's struggle to align industry and health, the FME is itself difficult to bookend and resolve. What becomes hidden is substantial variation in the health climate within which the industry was steeped, and the obscure logics by which certain industrial policies were prioritized over health needs.

For late industrial economies such as India, the means rhetoric is far more visible in the FME, contrasting with the ends rhetoric in the SME and TME. The FME offers the first environment in which the nation-state appears explicitly and self-consciously to foster industrial and health policies moving closer together. It was the first and only environment (Srinivas, 2012) where the range of instruments for policy and planning were so wide across both industry and healthcare; they are far less visible in later phases (see also Chaudhuri, 1986; Sahu, 1998; Srinivas, 2004).

These national politics of the FME include autonomous nationbuilding faced with immense hurdles of technology transfer and the realpolitik of picking international partner nations. The crucial point is that the FME was an important industrial development 'First', as well as a 'Market' first. It was the epitome of a nationally structured and regulated set of market environments across two phases (public and private sector industrial capabilities) aimed at building health successes.

The lion's share of attention has focussed on the technical details of the FME. Indeed, there is much to extol on the industry side. In comparison with Brazil, for instance, the sheer volume of Indian firms, 
and the concerted set of national industrial policies to keep out foreign firms, boost inward technology transfer and develop close state-business compacts, points to a redoubtable Indian advance. The broader notion of state capacity helps us less in explaining why the state was much less successful in ensuring better health delivery in later years, precisely when industrial capabilities were growing stronger. It is clear that simple causal explanations from industry to health or vice versa offer an incomplete analysis.

Sahu (1998), for example, clearly demonstrates how tenuous was the link to the technology frontier, and how contested in many respects (although ultimately collaborative) the relationship between firms and the government became in the effort to research, develop and manufacture at home. Indeed, some of the contention between domestic firms and the government was ultimately resolved precisely because the needs of the nation rose to the top, and this was accomplished both rhetorically as well as pragmatically (Chaudhuri, 1986; Sahu, 1998). This pragmatism at least at national policy levels allowed a series of joint initiatives for technology transfer to be put into place between Indian and foreign firms and research institutes. It is clear that some types of problem-solving - such as those focussed on technological learning were privileged over others.

The FME can be understood as a concerted national policy effort to synchronize the production of essential items to address several subsectors of health care needs and ensuring access for the population. This entailed an effort across multiple geographic territories, institutional navigation in India's complex quasi-federal system of central and state governments, and of different urban and rural development planning and governance contexts (Srinivas, 2012). Evidence of this diversity is seen today, where adjacent subnational states may vary noticeably in strategies and instruments to regulate their health industry and its firms. ${ }^{2}$ Indeed, we could argue that state capacity not only varies but that the need to problem-solve becomes more acute, not less, as technological capabilities advance. Waiting for industrial capabilities to evolve fully before systematically addressing health outcomes appears to be a dubious recipe.

Problem-solving capacity can therefore be termed the ability to frame, formulate and attempt to solve complex development challenges (see also Srinivas, 2014a). Problem-solving is arguably like exercising a muscle. The emphasis therefore is on the attempt to solve complex problems, not necessarily on solving them. The more one exercises the muscle (the attempt to solve), the stronger the muscle (ability to 
problem-solve) becomes. The big difference, however, is that the metaphor of exercising a muscle refers to single individuals, whereas the attempt to problem-solve complex problems requires institutional and organizational muscle. In other words, even if an individual might be able to think ahead to solutions, a truly complex social problem requires institutional and organizational mechanisms to experiment and seed the solution. This is what we might term 'the institutionalization' of the solution.

The tradition of using a grounded problem-solving approach is hardly new in development. Proponents such as Albert Hirschman (1967) used such thinking to probe public performance in development projects and to understand how political and economic reform occurred. Despite such a history of use, however, the more general idea of governance has risen to define and to shape concepts of state capacity, and the more specific problem-solving capacity has been obscured. One might even suggest that such problem-solving muscle should be the core of the state's capacity in development and health, especially for late industrial economies where such substantial technological capabilities are being fostered (Srinivas, 2014a). The FME is an inspirational story when analyzed as state capacity directed towards building technological capabilities. It provides a more cautionary tale when seen through the lens of state efforts in problem-solving for healthier populations.

\section{Problem-solving heuristics as a dynamic element of state capacity}

The rhetorical 'states versus markets' development debate is not very helpful in the dilemma of effective policy design. The institutional triad (Figure 10.1) is a heuristic developed in Srinivas (2012) to show a way to understand the evolution of the industry as a whole, and the timeline of the Indian case in comparison with others. It offers a first means of comparative analysis in problem-solving, and a long timeline to understand the difficult process of planning on three particular institutional fronts: (1) production, (2) consumption/demand and (3) delivery. The health industry, after all, has several complex relationships to consider and is not easily divided under traditional ministries and agencies. The Health Ministry, for example, may sometimes control the moral high ground, but the Industries Ministry drives the dynamics of investment and the returns of firms. The triad therefore makes the policy levers and their institutional environment more evident. It reminds us that there is no single good or bad option in absolute terms, but there always exist 


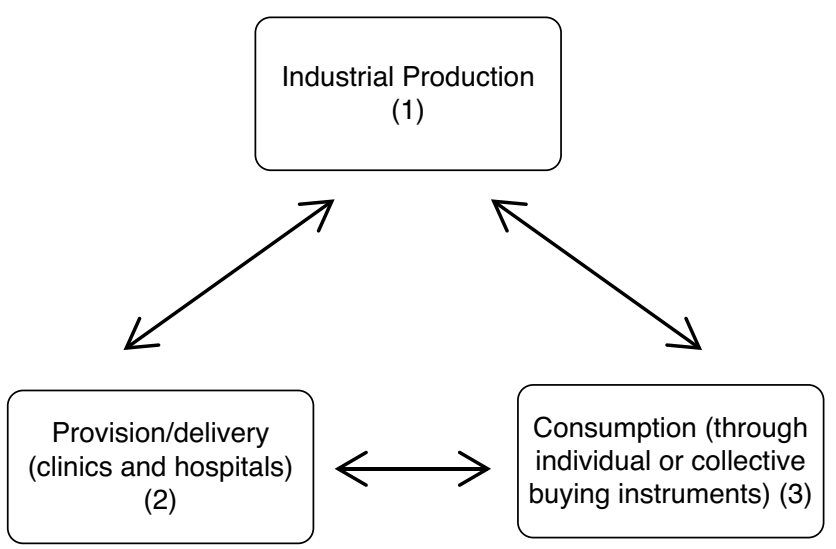

Figure 10.1 Institutional triad of health care Source: Srinivas (2012: 8; CCBY permission granted)

several, continual problem-solving choices to make in development terms.

The triad's three vertices refer to (1) production, (2) individual or collective consumption or demand and (3) delivery. States not only have to juggle any two; they have to juggle all three. As the Indian nationstate focussed in the FME on (1), the pressure to problem-solve arose in deepening capabilities in (1). For a problem-solving agency, the challenge is that every vertex is connected to every other, and outcomes are rarely causal. With the heuristic, I argued then that very few nations have successfully juggled all three vertices of the triad for any substantial length of time. We can say that developmental success is more likely as long as state agencies constantly attempt to exercise their problem-solving muscle.

Inevitably, if somewhere along the way the outcomes of development remain unprioritized, agencies are likely to be solving problems on which they have no agreement, which results in conflict. Yet we know that even in India there have been attempts to address more than one vertex. For example, states such as Karnataka in the south have been experimenting with boosting health insurance programs - often co-operative health insurance models - to build up consumption/demand (2) and improve delivery of hospitalization and certain outpatient services (3). Similarly, private hospital chains such as Apollo have been problemsolving in a more directed way with state health officials and national 
satellite agencies to boost telemedicine, a technology-driven service (long-distance consultation and diagnostics) which connects (1) and (3). Telemedicine is a way to solve specific types of problems and is not a panacea for all emergency, curative and primary care segments, but it can provide an important solution in many rural areas where access to medicines produced (1), demand (2) and delivery (3), can all face challenges.

Developmental problem-solving is surely context- and place-specific in strategy. Consider a competing, powerful, developmental view: that problem-solving has universal qualities; that what works in Gambia should work in India; or that one problem to be solved is very much like another. Older writing on development long recognized that problems were context-driven, did not require 'big-push' approaches, but had to grapple with the complexity and disequilibria of real-world and situated processes. Albert Hirschman, for instance, recognized that the aphorism of 'One thing at a time' is not always helpful in development, since context-specificity required relational strategies unique to places, so that one-at-a-time sequencing may not move the developmental dial (Hirschman, 1990, and his earlier 1967 work). Later, the idea of 'good enough governance' (Grindle, 2007) signalled relative solutions and relative performance of states, governments and bureaucracies. UNCTAD (2009, IV), for example, connects 'problem-solving energies' to democracy, but while democracy may be helpful to force frequent exercise, it is no guarantee either of setting development priorities or of the state's commitment to continue to exercise its problem-solving muscle.

When one acknowledges that the three vertices in Figure 10.1 are always changing with respect to the other and in response to more systemic factors, a focus on problem-solving can point to development plans that are patient. In such plans, long-term and short-term goals are set and process and outcomes can be measured. No state can attend to all three vertices at once, and technological learning, although it has crucial aspects in all dimensions of (1), (2) and (3), is nevertheless not sufficient alone. Therefore, development planning that is patient requires acknowledging that problem-solving is essential, with clear priorities and value-judgements that must be communicated, with measureable outcomes. It requires institutional design that constantly exercises and rewards this problem-solving muscle. For example, vaccine procurement can directly connect production (1) to demand (2) through ambitious buying and clear market signals, but unless the public health system is energized, delivery (3) may be problematic (see comparable arguments for Indian vaccines in Srinivas, 2006; Puliyel and Madhavi, 2008). 


\section{Putting patents in their place}

Once the emphasis is on problem-solving within the state, the design of realistic industrial policies can also take credible shape. New industrial policies can thus take on this problem-solving character, offering institutional mechanisms through which both productive capabilities and beneficial social indicators can be achieved (Srinivas, 2011; 2012). Technological advance and learning in these industrializing contexts is a specific type of problem-solving capability, but it offers no panacea.

Therefore, policies that are too narrow in terms of technological advance are unlikely to solve end problems. One example is the constant debate on patents. The Indian Patent Act 1970 was a crucial catalyst not just to reform the sector's production and access concerns but of the planning and reform process required to set new health goals. The Indian Patent Act 1970 was a mechanism to protect processes, not products, and was somewhat unexceptional relative to other countries. However, with the rise of Indian public and private sector successes and the use of the Patent Act as a protectionist tool, the Act became more internationally contentious and most visible in the context of the WTO TRIPS negotiations. The 1970 Act represented contested terrain: it was widely praised by those who wished to boost the learning capabilities of Indian firms on the one hand; praised also by those whose goal was more affordable access to medicines; and criticized by others who argued that the fillip it provided to learning was skewed towards 'imitation' and 'reverse engineering' rather than 'real' innovation. Finally, it was criticized for creating protectionist and regressive policies.

However, the First Market Environment shows that such unilinear explanations rely too heavily on patents to explain developmental outcomes; much wider problem-solving gaps existed. The carrots offered to firms were more extensive than just patents, and were ultimately defined by the state's priorities whatever the economic arguments might have been (see also Jacob, 2010: 83). In both the first and second phases of the FME, intellectual property rights (IPR) acted in concert with a range of other industrial instruments for competition, investment, infrastructure and a range of health institutional design issues (many of which remained unsuccessful). Process patents along with the Drug Price Control Order and these other policies forced lowered costs through competition (Abrol and Guha, 1986).

In the Second Market Environment, Indian firms and policy makers faced substantial new pressures to harmonize towards a product patent regime. Conflicting views of reform from bureaucrats and politicians 
underscored that problem-solving with regard to affordable access had no single narrative or political rhetoric during the trade harmonization negotiations (Jacob, 2010). The elites of the senior Indian Administrative Service (IAS) bureaucracy, for example, possessed considerable discretion and strategic flexibility in shaping policy design and its reform.

Patents offer monopoly protections but are second-best solutions. Acting alone, they rarely solve developmental challenges, although they may resolve trade pressures. Especially in the FME, patents required complementary industrial and social policies including clear foreign direct investment (FDI) guidelines, restrictions on monopolies, price controls, canalization of bulk drugs, rules for pharmacy procurement and use, assumptions about the capacity of clinics and hospitals and so on (Basant, 2010; Rai, 2009; Sahu, 1998; Srinivas, 2011, 2012). Some actively contend that the more one set of capabilities has advanced, the more firms have sought monopoly status and protections of all kinds. Madhavi (2013) states definitely that market guarantees and supports for public-private partnerships have worked to create the public sector's demise in vaccines.

\section{Getting better}

The FME's emphasis on universal access pointed policies towards essential medicines, especially public health priorities such as antibiotics. Combined with process patents and price controls, it induced competition and Indian production capabilities in both public and private sectors. The SME saw the introduction of the strongly worded New Drug Policy (NDP) (Government of India, 1978). However, the NDP presumed that item (5) below was necessarily at the right position and compatible with the other goals set out as:

1. To develop self-reliance in drug technology;

2. To provide a leadership role to the public sector;

3. To aim at a quick self-sufficiency in the output of drugs with a view to reduce the quantum of imports;

4. To foster and encourage the growth of the Indian sector;

5. To ensure that the drugs are available in abundance in the country to meet the health needs of our people;

6. To make drugs available at reasonable prices;

7. To keep a careful watch on the quality of production and prevent adulteration and malpractices; 
8. To offer special incentives to firms which are engaged in Research and Development; and

9. To provide other parameters to control, regulate and rejuvenate this industry as a whole, with particular reference to containing and channelizing the activity of foreign companies in accord with national objectives and priorities.

The aspirations on the list were noteworthy, but the NDP reflected many unresolved triad questions about value ordering of the vertices and phasing of priorities. They assumed, for example, that cheap and reliable production would solve access to medicines problems. It assumed that domestic production was a necessity, but also that such production combined with other items on the list was sufficient. Only the fifth item in the above list questions this concern most directly. ${ }^{3}$ The rest of the points notably address industrial production priorities and incentives. ${ }^{4}$

As Chaudhuri (1986) points out, foreign firms had to be forced into certain roles in the industry. Some of them had been established in India as early as 1923, began the domestic production of formulations only in 1955 and, despite a range of inducements through national pharmaceutical policies, had not begun producing bulk drugs even by 1978 . In contrast, several Indian firms had seized the opportunities to do so provided by the state. As I have argued about the FME (Srinivas, 2012: 67), 'India's unique gains in this period were due in part to a multi-pronged policy approach with politically defensible market entry points through "essential" drugs and protectionist restrictions. But politics would have been insufficient without systematic and demonstrable technology outcomes and the development agenda focused on the twin goals of process technology gains and affordable medicines'. By challenging multinational companies in the courts, through national government supports and through a range of bureaucratic interventions, through the use of monopoly restrictions, production allocation licenses, price controls and process patents, Indian problem-solving was already agile on the industrial front. With clearer priorities in health outcomes and deliberate problem-solving rewards, such problem-solving might have reached its highest point yet.

I recently argued that we should consider an evolving spectrum of need and demand (Srinivas, 2014b): Need that is not recognized as need; Need that is recognized as need but not as demand; to Recognized, but unfulfilled demand; and finally, Effective demand (what is traditionally 'demand') and labelled as (2) above. Indeed, part of the toolbox for problem-solving is to identify that which is invisible or for which market 
signals are inappropriate. Indian examples include the Jaipur Foot prosthetic and the Oral Polio Vaccine cases, both of which required a rich set of actors and organizations that painstakingly problem-solved. In the Jaipur foot prosthetic case, actors progressed from identifying needs to ensuring that those in need had artificial limbs that worked, were caringly customized or could be easily repaired. These were especially rewarding outcomes because while road accidents in India had seen staggering rises, the state responded pitiably. The Jaipur Foot required a strong charitable organization in India to take need to demand in various forms, while all the while improving both the technology of prosthetics appropriate to the country and attempting to meet both domestic and export needs. Ensuring both production and then delivery of Oral Polio Vaccines (introduced in 1978, the same year the NDP came into force) required non-market instruments. This was because although vaccines were free through government programs, they were not easily available or, where available, not taken up. Here, too, an immense effort was state-led but richly enhanced by non-state partnerships.

Two successes further exemplify the potential of well-honed problemsolving led by, but not limited to, the state. One is India's sustained and unsurpassed success in block-level planning and wide administrative and spatial spread for polio immunizations. Private, non-profit organizations, religious groups, labour unions, and many others have thus played vital roles in identifying the needs-demand spectrum for policy makers and health administrators.

The second is emerging urban evidence of success and learning from Surat City. Surat, in dealing with plague and then floods, developed systematic improvements in disease surveillance. In India's polio success and in Surat's ambitious disease surveillance, industrial capabilities for polio vaccines or diagnostic kits and antibiotics were necessary but not sufficient. Challenges after all still remain for Surat in its current response to swine flu and its citywide integration of differentiated and localized community-level surveillance systems. Both polio and Surat have also brought to the fore India's continued administrative challenges in solving last-mile access issues, and the importance of partnerships local and international - in building experimentation and learning.

Problem-solving in the realm of vertex (2) therefore requires administrators to anticipate how (1) and (3) may be speaking to the effective demand of (3) but not solving the deeper developmental 'hidden' needs (see also Mitra, 1986). At the end of a good problem-solving process, in other words, one should be able to see beyond the obvious. The muscle should begin carrying more problem-solving weight and be 
more flexible. Problem-solving skills can therefore be collective, both within and outside the state. Both polio and disease surveillance cases exemplify persistent problem-solving exercises through a wider set of governance networks which included the state, firms, NGOs and other community partners. They also exemplify a clear need for connecting market and other instruments to a territorial agenda: national but operating through block-level strategies in the polio case, and citywide and neighbourhood strategies for Surat.

An illustrative case of less successful problem-solving demonstrates the difference between access in principle versus access in practice. Bengaluru (Bangalore) City in Karnataka state is possibly one of India's best sites for medical innovation, and for quality and range of health facilities, yet suffers from an unfortunately common lack of attention to sustained problem-solving. ${ }^{5}$ In the $2012 \mathrm{H} 1 \mathrm{~N} 1$ outbreak and in the 2015 outbreak of swine flu, Bengaluru faced an unchanged situation: doctors struggled in government research institutes and treatment centres to obtain antibiotics and diagnostic kits. International procurement of diagnostic kits was successful and had ironically steered both state and manufacturer away from production to address the domestic crises (see also Srinivas, 2006). ${ }^{6}$ By 2015 , little sustained problem-solving had occurred in the state health system in the intervening three years since $\mathrm{H} 1 \mathrm{~N} 1$, and the city's doctors and patients experienced an alarming sense of deja $v{ }^{7}{ }^{7}$

Yet, problem-solving has to be patient. Oral polio vaccines were introduced in 1978. By 2011, India had become polio-free and by 2014 the three-year cautionary timeline had passed. State problem-solving is never apolitical in this timeline. It may engender bitter debates about the need for privatization or allegations of fraud. For instance, there has been debate about whether national government policies, which in the FME were seen as progenitors of public health, have since deliberately undermined public sector production capabilities in vaccines; furthermore, that such policies exaggerated demand data to justify a growing role for the private sector's profits (Madhavi, 2003; Puliyel and Madhavi, 2008). Worse still is the claim that epidemiological evidence was deliberately sidelined and a 'techno-centrism' adopted in designing vaccine policy (Bajpai and Saraya, 2012), where advance market commitments to new technologies have outstripped 'evidence-based vaccine policies' (Madhavi, 2013). The FME and SME strengthened vaccine production capabilities and created important procurement spaces for priority medicines and vaccines. Multilateral and international vaccine procurement played a much weightier role in the SME in boosting the private 
sector and creating some tensions between state regulation of exports and domestic uptake.

Therefore, rather than reaching far too wide by seeing state capacity as a normative function across the entire period of productive capabilities, and rather than depending too heavily on the diffuse notion of growing 'good governance', a focus on problem-solving requires policy and planning on the ground to become directed and valueexplicit: for example 'Everyone - no matter what their economic or social status - should have real, measurable access to affordable medicines, vaccines, or diagnostic kits. This priority policy will be enforceable by 2020 and will carry explicit penalties for non-performance of government agencies or for those seeking windfall private profits but not delivering better access ${ }^{\prime}{ }^{8}$ Problem-solving, in other words, is a core state capacity. When done well, problem-solving in the state's line agencies forces dilemmas and discussions about value-propositions that have then to be designed by networks of actors into policy and last-mile planning.

\section{Conclusion: strong production, weak problem-solving in health}

The FME was perhaps the most ambitious market environment in the convergence it sought between industry and health goals, and the most overt in these ambitions. These ambitions were seen in decisions by the bureaucracy, through judicial judgements and legal battles against multinational firms, through recognition of personnel and delivery needs. Yet, was this ambition manifested in sustained problem-solving at multiple scales of governance? No.

Indian drug policies, wittingly or not, delinked industrial growth from health needs, even while the state made several market restructuring attempts in order to build capabilities. With the exception of priority national health programs, centralized planning targets were focussed on production capacity and far less on incentives for demand uptake of this capacity and delivery. Despite the rhetoric of grassroots mobilization and rural devolution, there were weak decentralized health plans. The industrial priorities of the pharmaceutical industry were resolved conservatively within the institutional contours of the Ministry of Chemicals and Fertilisers rather than those provided by the Ministry of Health.

While the national government offered carrots and sticks for private domestic firms, these focussed mainly on technological advances and 
market concentration. These incentives encouraged diversification, dominance in bulk drugs, process patents and price controls that placed caps on health spending and boosted competition. Abrol and Guha (1986), for instance, argue that while the country successfully moved from formulations capability into more challenging bulk drugs, quality consistency suffered. Madhavi (2003) and others have argued that over time and with growing technological capabilities, private suppliers became emboldened in dictating policy design to the state, favouring their own profits over people's health. Technological advance makes domestic resolution of the health industry's priorities more, not less, complex in late industrial economies (Srinivas, 2012).

Yet Indian health and industrial goals were quite decisive and convergent in Phase I of the FME when the public sector was involved. After all, national priorities and institutionalized problem-solving were largely equivalent to the priorities and problem-solving in nationally owned public sector firms. However, the problems and the multitude of actors grew as the FME progressed, and the problem-solving capabilities, although in principle greater, were diffused through the private sector and became more difficult for the state to regulate. At no time during the FME could quality, safety or guaranteed redress be assured. The value priorities related to needs became ironically more obscured by growing technological capabilities and by the attractions of the foreign markets and growing export earnings.

Some nations thus begin problem-solving by creating domestic health delivery as the priority even if they import, while other nations do as India did, developing and deepening their industrial supply. India triumphed in the latter dimension. Yet, there is no 'best' starting point for any problem-solving; its value-basis, systemic linkages and context make it so - points recognized also by Hirschman $(1967 ; 1990)$. The triad is a perpetually co-evolving system in which states make continual improvements and build institutional ties (Srinivas, 2014a). Problemsolving requires institutions that are agile, staff and rules that are both flexible but oriented towards timely outcomes, and outcome measures that are clear, transparent and can be monitored and enforced. Without these credible commitments to problem-solving towards health outcomes, more generalized state capacities become irrelevant and illegitimate.

Two market environments have now passed, and a third arguably is still under way with biotechnologies changing how we contend with all aspects of health care. The decades since 1950 have demonstrated that Indian production of generic medicines, diagnostic kits, 
biopharmaceuticals and vaccines has grown stronger and ever more sophisticated. In the absence of regular exercise to connect its vertices, however, the triad remains slack and the state's problem-solving muscles weakened. Rather than resembling a dynamic, co-evolving triad, the result is then an ossified triangle with its base vertices unable to dictate terms to its apex.

\section{Notes}

Acknowledgements: My thanks to Maureen Mackintosh and Geoff Banda for the invitation to participate in this book; to them and to Watu Wamae for insightful comments on the draft; and to Radha Ray and the Open University IKD team for making the London stays so pleasurable. This has been an intellectually generous and well-managed research effort. It is my good fortune to have had this opportunity to extend my research, exchange ideas with a great workshop team and receive comments from strong editors.

1. See Sahu's (1998) slightly different periodization but whose emphasis is also on production capabilities.

2. For example, Karnataka state in South India has experimented quite substantially with health care insurance systems (demand) and new pharmaceutical stocking and distribution practices (delivery). Although quite progressive in this regard, it has no deliberate state or urban administrative mechanisms to test the integration regularly.

3. See also Stoker and Jeffery (1988: 565).

4. For the range of specific cases, and contentions and ambiguities, see Sahu (1998) and Srinivas $(2006,2012)$. Stoker and Jeffrey (1988) discuss the New Drug Policy and foreign firms. The Astra-IDL case emphasized that foreign firms benefitted from the state's unresolved priorities. Most of its arguments about producing a drug already available in India were to emphasize the novelties in production process and the foreign exchange savings to the country. Most questions from bureaucrats to Astra in turn focussed on manufacturing details, employment and local industry effects, and financial priorities such as royalties, branding, export priorities and shares (Ibid: 565).

5. In the Hindu newspaper story, the same leading Head of Department of Neuro-Virology in Bangalore NIMHANS admits to shortages of $A(\mathrm{H} 1 \mathrm{~N} 1)$ testing kits, and although orders had been placed, they had to stop testing because of the unfulfilled orders; http://www.thehindu.com/news/national/ karnataka/shortage-of-ah1n1-testing-kits-worries-patients/article3359557. ece, last accessed 27 December 2014.

6. http://www.deccanherald.com/content/459453/state-facing-shortage-swineflu.html, last accessed 29 March 2015. Srinivas (2006) makes a similar point that international vaccine procurement programs had offered important benefits to Indian firms. However, Indian regulators and health administrators would have to redesign Indian vaccine policies and plans in order to attend to domestic health priorities. Madhavi $(2003,2013)$ emphasizes the undue influence exerted by private firms on state priorities.

7. See also Kotwani et al. (2007) on uneven availability of common drugs. 
8. Although former Prime Minister Indira Gandhi made her famous Alma Ata speech at the WHO on not allowing profiteering from life or death, she did not unfortunately vow to boost problem-solving alongside.

cc (i) Except where otherwise noted, this work is licensed under a Creative Commons Attribution 4.0 Unported License. To view a copy of this license, visit https://creativecommons.org/version4 